\title{
Gender Differences in Occupational Exposure Patterns
}

Amanda Eng, Andrea 't Mannetje, Dave McLean, Lis Ellison-Loschmann, Soo Cheng, Neil Pearce.

Centre for Public Health Research, Massey University, Wellington, New Zealand

Keywords: occupational exposures; gender; gender differences; workforce survey; epidemiology

Word count:

\section{Address for correspondence:}

Amanda Eng

Centre for Public Health Research

Massey University Wellington Campus

PO Box 756, Wellington

New Zealand

Phone: +64 48014986

Fax: $\quad+6443800600$

Email: a.j.eng@massey.ac.nz

Website: http://publichealth.massey.ac.nz 


\begin{abstract}
Objectives:

We conducted a population-based survey to examine gender differences in occupational exposure patterns and to investigate whether any observed differences are due to: a) gender differences in occupational distribution; and/or b) gender differences in tasks within occupations.
\end{abstract}

\title{
Methods:
}

Men and women aged 20-64 years were randomly selected from the Electoral Roll and invited to take part in a telephone interview, which collected information on selfreported occupational exposure to specific dusts and chemicals, physical exposures, and organisational factors. We used logistic regression to calculate prevalence odds ratios (OR) and 95\% confidence intervals (CI) comparing the exposure prevalence of males $(n=1,431)$ and females $(n=1,572)$, adjusting for age. To investigate whether men and women in the same occupation were equally exposed, we also matched males to females on current occupation (5-digit code) $(n=1,208)$ and conducted conditional logistic regression adjusting for age.

\section{Results:}

Overall, male workers were two to four times more likely to report exposure to dust and chemical substances, loud noise, irregular hours, night shifts, and vibrating tools. Women were $30 \%$ more likely to report repetitive tasks and working at high speed and more likely to report exposure to disinfectants, hair dyes, and textile dust. When men were compared with women with the same job title, gender differences were attenuated. However, males remained significantly more likely to report exposure to welding fumes, herbicides, wood dust, solvents, tools that vibrate, irregular hours, and night shift work. Women remained more likely to report repetitive tasks and working at high speed, and in addition were more likely to report awkward or tiring positions compared to men with the same job title.

\section{Conclusion:}

This population-based study showed substantial differences in occupational exposure patterns between men and women, due to both gender differences in occupational distribution as well as the gender segregation of tasks within the same job. 


\section{INTRODUCTION}

Women's work has traditionally been considered safe and less hazardous to health in comparison to men's work.[1] This has resulted in a lack of information on occupational hazards for women workers, [2] and our knowledge of occupational health and priorities for improving it have mainly been based on studies of men. However, some studies have observed clear gender differences in occupational morbidity, with men generally having higher rates of work-related injuries, cancer, hearing disorders, and vibration-related diseases, whereas females are more likely to be affected by upper musculoskeletal disorders, workplace bullying, and sexual harassment.[3] Gender differences in occupational distribution i.e. men and women working in different jobs and therefore being exposed to different risk factors, play an important role in many of these differential outcomes.[3] However, differences in occupational morbidity have also been observed for men and women with the same job title, suggesting that even in the same occupation, men and women are not equally exposed to particular risk factors for disease.

Understanding gender differences in occupational exposure, both between and within occupations, is a necessary first step towards understanding gender differences in occupational morbidity. However, very few studies have investigated the prevalence of occupational risk factors in women workers, or compared the distribution of risk factors between women and men. We conducted a population-based survey to examine gender differences in occupational exposure patterns and to investigate whether any observed differences can be explained by: a) gender differences in occupational distribution; and/or b) gender differences in tasks within occupations. 


\section{METHODS}

We conducted a nationwide telephone survey of a random sample of the New Zealand population aged 20-64 years over a 2-year period (2004-2006). The detailed study methodology is described elsewhere.[4] Briefly, 10,000 potential participants were randomly selected from the Electoral Roll and sent a letter of invitation to take part in a telephone interview. The interview obtained information on lifetime work history (for jobs with minimum six months duration), current exposures and workplace practices, and questions on selected health outcomes.

Participants were asked whether the following exposures were present (yes/no) in their current work environment: dust; smoke or fume; gas; oils and solvents; acids or alkalis; fungicides, insecticides, herbicides or timber preservatives; and other chemical products (including dyes, inks, and adhesives). If a participant indicated exposure(s), they were also asked to state the name and source of the substance. Participants were also asked how often their current job involved exposure to physical and organisational factors, including awkward or tiring positions, awkward grip or hand movements, lifting, carrying out repetitive tasks, working at very high speed, working to tight deadlines, standing, using tools that vibrate, and loud noise (all the time, three quarters of the time, half of the time, one quarter of the time, or never). The questionnaire obtained information on whether participants worked for at least three hours between midnight and 5am in the previous four weeks (night shift) and whether they regularly worked outside the hours of $8 \mathrm{am}-5 \mathrm{pm}$ (irregular hours). Participants were also asked to rate how stressful they found their current job on a 5point scale (not at all stressful, mildly stressful, moderately stressful, very stressful, or 
extremely stressful). In addition, we asked individuals the ages of the members in their household and whether these people required looking after by the participant. The variable 'household responsibility' was created based on a positive report of looking after children (0-18 years) or elderly dependents (60+ years) in the household.

Occupations were coded using the New Zealand Standard Classification of Occupations (NZSCO) 1999.[5] Differences in current workplace exposure between men and women were assessed using prevalence odds ratios (OR)[6] and 95\% confidence intervals (CI) using the unexposed as the reference group for each occupational exposure. In the case of job stress, individuals reporting no or mild work-related stress formed the reference group. We conducted unconditional logistic regression in STATA v10.0, adjusting for age (continuous variable).

To investigate whether gender differences in exposure were only due to gender differences in occupational distribution or could also be due to differences within occupations, we also conducted matched analyses where each male participant was matched (1:1) with a female participant on current occupation (5-digit NZSCO code). ORs and 95\% CIs were calculated using conditional logistic regression adjusting for age.

Categories of specific occupational exposures (yes/no), for example acetone, caustic soda, timber treatment, were created using a word search programme developed in SAS (version 9.1). The programme was designed to search keywords (including alternative spelling and trade names) in the "name of substance" and "source of 
substance" text fields. For each newly created exposure category, the original text was checked to ensure that the new category captured all of the exposed participants.

\section{RESULTS}

A total of 3,003 interviews were completed (the response rate was 37\%). The characteristics of the total sample and the sample of males and females matched on occupation are described in Table 1 . Women comprised just over one half of the total sample. In both samples, there was a higher proportion of females in the 35-44 year age group, a lower proportion in the oldest age group (55+ years), and a slightly higher proportion of Māori (the indigenous population of New Zealand) females than males. In the total sample, there were higher proportions of females in the professionals, technicians and associate professionals, clerks, and service and sales workers groups, whereas there were higher proportions of males in the legislators, administrators and managers, agricultural and fishery, trades, and plant and machine operators and assemblers groups. There were similar numbers of men and women in the elementary occupational group.

Table 2 compares the prevalence of various occupational exposures between males and females in the total sample $(n=3,003)$, and between males and females in the same occupation (referred to as the matched sample; $n=1,208$ ). In the total sample, male workers were more than twice as likely to report exposure to dust and chemical factors. Males were also more likely to be exposed to loud noise $(\mathrm{OR}=2.70 ; 95 \% \mathrm{CI}$ 2.29-3.18); use tools that vibrate $(\mathrm{OR}=3.80 ; 95 \%$ CI 2.94-4.90); work night shift in the previous month $(\mathrm{OR}=2.57 ; 95 \% \mathrm{CI} 1.89-3.50)$ and work irregular hours 
$(\mathrm{OR}=1.76 ; 95 \% \mathrm{CI} 1.44-2.15)$. On the other hand, women were $32 \%$ more likely to report carrying out repetitive tasks $(\mathrm{OR}=0.76 ; 95 \% \mathrm{CI} 0.65-0.89)$ and $33 \%$ more likely to report working at very high speed $(\mathrm{OR}=0.75 ; 95 \% \mathrm{CI} 0.65-0.87)$ a quarter of the time or more. Females were also $52 \%$ more likely to report looking after children (0-18 years) or elderly dependents $(60+$ years $)$ in their household $(\mathrm{OR}=0.66 ; 95 \% \mathrm{CI}$ 0.57-0.78).

\section{Matched sample}

There were 827 male participants with no female match for job code and they were subsequently excluded from the matched analyses. For most exposures, matching on occupation attenuated gender differences in exposure (i.e. for the dust and chemical factors, $67-87 \%$ of the excess risks observed for males were due to gender differences in occupational distribution). However, compared to women with the same job title, men were still more likely to report exposure to smoke/fume/gas (OR=1.54; $95 \% \mathrm{CI}$ 1.11-2.14) and oils and solvents ( $\mathrm{OR}=1.62 ; 95 \% \mathrm{CI} 1.16-2.27)$. Men were also twice as likely to use tools that vibrate $(\mathrm{OR}=2.06 ; 95 \% \mathrm{CI} 1.29-3.29)$ and work irregular hours $(\mathrm{OR}=1.97 ; 95 \% \mathrm{CI} 1.37-2.83)$, and three times more likely to work night shifts $(\mathrm{OR}=3.32 ; 95 \% \mathrm{CI} 1.73-6.36)$ compared to women with the same job title. Men also appeared to be $50 \%$ more likely to report job stress compared to women in the same occupation.

Compared to men with the same job title, female workers were $28 \%$ more likely to report carrying out repetitive tasks (OR=0.78; 95\% CI 0.59-1.01), $43 \%$ more likely to report working at very high speed $(\mathrm{OR}=0.70 ; 95 \% \mathrm{CI} 0.55-0.89)$, and $37 \%$ more likely to report awkward or tiring positions ( $\mathrm{OR}=0.73$; 95\% CI $0.57-0.92)$. The 
decreased odds for men of household responsibility increased towards the null value after matching on occupation but remained decreased by $24 \%(\mathrm{OR}=0.76 ; 95 \% \mathrm{CI}$ 0.59-0.98).

\section{Specific occupational exposures}

Table 3 compares the prevalence of specific occupational exposures between men and women for the total and matched samples.

Of the 61 specific exposures under study, 43 were more common among men $(p<0.05)$ in the total sample. Specific exposures more than 10 times more common in the male working population compared to the female working population included: hydraulic oil; welding fumes; paint thinner; paint dust; kerosene; diesel fuel; printing; insulation material; sulphuric acid; timber treatment; fibreglass; and cutting fluid. Of the 61 specific exposures under study, 6 were more common among women $(p<0.05)$ : hair dye; textile dust; household dust; environmental tobacco smoke (ETS); bleach; and disinfectant. When comparing men and women with the same job title, 4 exposures remained significantly more common in men: welding fumes, herbicides, wood dust, and solvents. 


\section{DISCUSSION}

This study aimed to estimate the gender differences in occupational exposure in a representative sample of the working population of New Zealand.

The study has several limitations. Firstly, the response rate was relatively low (37\%) and the implications of this are discussed in more detail elsewhere.[4] Briefly, differences between participants and non-participants were observed for age, ethnicity, deprivation, and certain occupational groups. However, these differences were similar for males and females and gender did not appear to be a significant determinant of refusal to participate or non-contact.[7] The analyses presented here are also adjusted for possible determinants of non-response (e.g. age), and it is therefore unlikely that the observed gender differences in exposure are due to gender differences in survey participation.

Secondly, the characterisation of exposure in this study was based on self-report, thus we cannot rule out the possibility that gender differences in reporting or perception of exposure contributed to the results. However, a Swedish study reported no differences in the validity of reporting physical risk factors for musculoskeletal disorders between men and women.[8] Thirdly, the analyses only assessed exposure prevalence in the current job and did not take into account duration or intensity of exposure, which may also impact on gender differences in exposure and ultimately gender differences in occupational health. For example, female workers are more often employed part-time and therefore more likely to experience cumulative exposure. Another limitation of 
the study is that the numbers did not permit matching males and females on occupation and specific industry. For example, for the job title 'sales worker', females are more likely to work in retail sales whereas men are more likely to work as manufacturers' representatives (cited in Messing et al [2]).

On the other hand, this study has several important strengths. Firstly, the men and women covered by this survey were representative of the total working population, as opposed to similar studies that were limited to selected occupation or industry groups.[9, 10] Secondly, gender differences were investigated for a wide range of occupational exposures, including specific chemical and physical exposures, as well as organisational factors and stress, thus not only focusing on exposures traditionally associated with men's work. Thirdly, this is the first study that not only quantified the gender differences in occupational exposure at the population level, but also investigated whether any gender differences in occupational exposure exist for men and women working in the same occupation. Therefore it was possible to investigate whether the observed gender differences in occupational exposure were entirely due to: a) the segregation of men and women into different occupations; or could also be due to b) men and women with the same job title carrying out different tasks.

This study found that men were more likely to be exposed to many of the workplace substances under study. They were also more likely to be exposed to loud noise, vibrating tools, night shift work, and irregular hours. On the other hand, women were more likely to report repetitive tasks, working at high speed, and exposure to certain workplace substances. These findings were not surprising considering that throughout the industrialised world, men and women are concentrated in different jobs and 
industries; women are more likely to work as professionals (particularly in health and education), service and sales workers, and clerks (typically characterised by fastpaced and repetitive work tasks), while men are more likely to work in the agricultural, trades, and manufacturing sectors (typically characterised by exposure to dusts and chemicals and to physically demanding tasks such as heavy lifting). In this study, the actual gender differences in occupational exposure prevalence are quantified, showing that for general exposure categories the gender difference in prevalence can be up to a factor of 4 while for more specific occupational exposures the gender difference can be more than a factor of 10 . The reported quantitative estimates for exposure prevalence in men and women can be useful in occupational health studies focusing on both genders and where information on exposure is not available.

We also found that the different occupational distributions of men and women explained most of the observed differences in exposure prevalence; $67-87 \%$ of the excess in exposure to workplace substances, $88 \%$ of the increased odds of exposure to loud noise, and $100 \%$ of the moderate excess in exposure to lifting were explained by differences in occupation between men and women. The European Working Conditions Survey (EWCS) also reported that occupational distribution played a major role in observed gender differences in chemical and physical exposures.[11] In contrast, a cross-sectional study in the U.S. (36\% women) reported that there were no major differences between men and women for exposure to dust, chemicals, noise, and hand repetitions before and after adjusting for industry/job. However, this study only examined four industries in a limited socioeconomic range.[12] 
This study also found that, even after accounting for gender differences in occupation, gender differences in prevalence remained for several exposures; males were still more likely to report exposure to smoke/fume/gas, oils and solvents, vibrating tools, night shift work, and working irregular hours compared to females in the same occupation. Female workers were more likely to report repetitive tasks, working at very high speed, and awkward or tiring positions compared to their male counterparts. For the specific categories of workplace substances, in general, men were more likely to report exposure than women, even within the same occupation.

These findings suggest that men and women with the same job title do not always carry out the same tasks. A few studies have examined men and women with the same job title and reported a gendered assignment of tasks.[1, 9, 13, 14] Several studies have reported that women are more likely to perform repetitive tasks compared to men in the same job.[10, 15, 16] However, these studies have been based on small numbers or one specific occupational group. Differences in task assignments by gender could be due to the different physical capabilities of men and women or socialised gender roles. The greater relative stature and muscular strength of men compared to women makes them perceivably more suited to physically demanding tasks such as heavy lifting. The same argument can be applied to the suitability of tasks involving dexterity and precision (and therefore repetitiveness) for women. However, Messing argues that social constructions of what is suitable work for men and women also play a role and many physical tasks assigned to men can be adapted to women.[1] For example, in an observational study of hospital cleaners, Messing et al. concluded that there was no clear reason why women could not perform the 'heavy' work typically assigned to men.[14] 
In the current study women were not more likely to report high levels of job stress. Men were $52 \%$ more likely to report moderate stress and $43 \%$ more likely to report a very or extremely stressful job compared to females in the same occupation. A New Zealand study of 41 companies reported a higher risk of work-related stressors for men, even after adjusting for occupation.[17] While women generally report more workplace stressors and poorer psychosocial working conditions than men, the current evidence for a gender difference in work-related stress as an outcome is inconsistent.[3]

The dual exposure of work demands and responsibility for the household may also impact on the relationship between exposure and health, particularly for women. The responsibilities for housework and childcare still largely fall on women. The current study found that women were $52 \%$ more likely to report looking after children (0-18 years) or elderly dependents in their household compared to men. This excess attenuated after matching on occupation but remained elevated at $32 \%$. The New Zealand Time Use Survey reported that women carry out more unpaid work than men regardless of employment status.[18] The burden of household responsibilities may result in increased exposure to physically demanding activities as well as less time for recovery after work. Several studies have shown that women spend less time exercising or relaxing outside of work hours compared to men.[15] In addition, the responsibility for childcare may also restrict the type of work women can do e.g. parttime work which is often associated with routine and repetitive work and lower job control. Unpaid work is an important aspect of women's occupational health and safety and is rarely investigated in epidemiological studies. 
In conclusion, this study has found that even in acountry such as New Zealand, with relatively good gender equality in employment opportunities, men and women are far from equally exposed to occupational risk factors for disease. Male workers continue to experience a heavier burden of occupational exposure to most dusts and chemicals and certain physically demanding tasks. However, it should be noted that for many of these occupational exposures, the prevalence in women workers was not negligible. For example, $7 \%$ of female workers reported exposure to solvents and $4 \%$ reported exposure to engine emissions in the overall sample. Compared to men, women workers had a higher prevalence of repetitive tasks, working at very high speed, and certain exposures such as disinfectants, hair dyes, and textile dust. Gender differences in exposure were in part explained by gender differences in occupational distribution, while for some exposures differences in prevalence were even observed for men and women with the same job title. Therefore, there is a need for caution when using job titles as a surrogate for exposure. This study illustrates that gender has a substantial impact on occupational exposure prevalence, even within the same job, and that the influence of gender should not be overlooked in occupational health research.

\section{What this paper adds}

- The majority of occupational health and exposure assessment studies have traditionally been carried out in men. Therefore, very few studies have 
compared the distribution of occupational risk factors between women and men.

- There are substantial differences in occupational exposure patterns between men and women. Both gender differences in occupational distribution and gender differences in tasks within occupations contribute to these disparities.

- The influence of gender should not be overlooked in occupational health research. 
This project was funded from a Joint Research Portfolio of the Health Research Council, the Accident Compensation Corporation, and the Department of Labour which issued a Request for Proposals (RFP) for a study of the burden of occupational ill-health in New Zealand (HRC 04/072). The Centre for Public Health Research is supported by a Programme Grant from the Health Research Council of New Zealand (HRC 02/159). We also thank Tracey Whaanga, Zoe Harding, Cecil Priest, Penelope Whitson, Michaela Skelly, Phoebe Taptiklis, Emma Drummond, Anna McCarty, Natasha Holland, Kelly Gray, Adam Hoskins, Alister Thomson, Jessica Fargher, Cilla Blackwell, Emma Turner, Selena Richards, Kim Crothall, Alice Harding, Joelene Wilkie, Joanne Dow, and Tania McKenzie who conducted the interviews, and Rebecca Jones, Alice Harding, Zoe Harding, Alister Thomson, Chani Tromop van Dalen, Jessica Fargher, Cecil Priest, and Miria Hudson who completed the data entry.

\section{REFERENCES}


1 Messing K. One-eyed science: occupational health and women workers. Philadelphia, PA: Temple University Press. 1998:162-3.

2 Messing K, Punnett L, Bond M, et al. Be the fairest of them all: Challenges and recommendations for the treatment of gender in occupational health research. Am J Ind Med. 2003;43(618-629).

3 Mannetje A, Slater T, McLean D, et al. Women's occupational health and safety in New Zealand. National Occupational Health and Safety Advisory Committee. 2009; Technical report 13, Wellington.

4 Eng A, Mannetje A, Cheng S, et al. The New Zealand Workforce Survey I: Selfreported occupational exposures. Ann Occup Hyg. 2010;54:144-53.

5 Statistics New Zealand. New Zealand Standard Classification of Occupations 1999. Wellington 2001.

6 Pearce N. Effect measures in prevalence studies. Environmental Health Perspectives. 2004;112:1047-50.

7 Mannetje A, Eng A, Douwes J, et al. Determinants of nonresponse in an occupational exposure and health survey in New Zealand. Submitted for publication. 2009.

8 Leijon O, Wiktorin C, Harenstam A, et al. Validity of a self-administered questionnaire for assessing physical work loads in a general population. $J$ Occup Environ Med. 2002;44:724-35.

9 Nordander C, Ohlsson K, Balogh I, et al. Fish processing work: the impact of two sex dependent exposure profiles on musculoskeletal health. Occup Environ Med. 1999;56:256-64.

10 Hooftman W, Beek Avd, Bongers P, et al. Gender differences in self-reported physical and psychosocial exposures in jobs with both female and male workers. $J$ Occup Environ Med. 2005;47:244-52.

11 Burchell B, Fagan C, O'Brien C, et al. Working conditions in the European Union: the gender perspective. European Foundation for the Improvement of Living and Working Conditions. 2007.

12 Quinn M, Sembajwe G, Stoddard A, et al. Social disparities in the burden of occupational exposures: results of a cross-sectional study. Am J Ind Med. 2007;50:861-75.

13 Messing K, Dumais L, Courville J, et al. Evaluation of exposure data from men and women with the same job title. J Occup Med. 1994;36(8):913-7.

14 Messing K, Chatigny C, Courville J. 'Light' and 'heavy' work in the housekeeping service of a hospital. Appl Ergon. 1998;29(6):451-9.

15 Strazdins L, Bammer G. Women, work and musculoskeletal health. Soc Sci Med. 2004;58:997-1005. 
16 Silverstein B, Fine L, Armstrong J. Hand wrist cumulative trauma disorders in industry. Br J Ind Med. 1986;43:779-84.

17 Dryson E, Scragg R, Metcalf P, et al. Stress at work: an evaluation of occupational stressors as reported by a multicultural New Zealand workforce. Int J Environ Health 1996;2(1):18-25.

18 Statistics New Zealand. Around the clock: findings from the New Zealand Time Use Survey 1998-99. Wellington, Statistics New Zealand. 2001. 


\begin{tabular}{|c|c|c|c|c|c|c|c|c|c|c|c|c|c|c|}
\hline & \multicolumn{7}{|c|}{ Total sample } & \multicolumn{7}{|c|}{$\begin{array}{l}\text { Matched sample (males and females with the same } \\
\text { occupation) }\end{array}$} \\
\hline & \multicolumn{2}{|c|}{ Total } & \multicolumn{2}{|c|}{ Male } & \multicolumn{2}{|c|}{ Female } & \multirow[t]{3}{*}{$\mathrm{Chi}^{2}$} & \multicolumn{2}{|c|}{ Total } & \multicolumn{2}{|c|}{ Male } & \multicolumn{2}{|c|}{ Female } & \multirow[t]{3}{*}{$\mathrm{Chi}^{2}$} \\
\hline & \multicolumn{2}{|c|}{$\mathrm{N}=3003$} & \multicolumn{2}{|c|}{$N=1431$} & \multicolumn{2}{|c|}{$\mathrm{N}=1572$} & & \multicolumn{2}{|c|}{$N=1208$} & \multicolumn{2}{|c|}{$\mathrm{N}=604$} & \multicolumn{2}{|c|}{$\mathrm{N}=604$} & \\
\hline & $\mathrm{N}$ & $\%$ & $\mathrm{~N}$ & $\%$ & $\mathrm{~N}$ & $\%$ & & $\mathrm{~N}$ & $\%$ & $\mathrm{~N}$ & $\%$ & $\mathrm{~N}$ & $\%$ & \\
\hline \multicolumn{15}{|l|}{ Age at interview } \\
\hline 20-34 years & 659 & 21.9 & 302 & 21.1 & 357 & 22.7 & & 292 & 24.2 & 137 & 22.7 & 155 & 25.7 & \\
\hline $35-44$ years & 820 & 27.3 & 349 & 24.4 & 471 & 30.0 & & 308 & 25.5 & 140 & 23.2 & 168 & 27.8 & \\
\hline $45-54$ years & 868 & 28.9 & 404 & 28.2 & 464 & 29.5 & & 332 & 27.5 & 168 & 27.8 & 164 & 27.2 & \\
\hline $55+$ years & 656 & 21.8 & 376 & 26.3 & 280 & 17.8 & $p<0.01$ & 276 & 22.9 & 159 & 26.3 & 117 & 19.4 & $\mathrm{p}=0.02$ \\
\hline \multicolumn{15}{|l|}{ Ethnicity } \\
\hline Māori & 273 & 9.1 & 109 & 7.7 & 164 & 10.4 & & 106 & 8.8 & 42 & 7.0 & 64 & 10.6 & \\
\hline Non-Māori & 2724 & 90.9 & 1,316 & 92.4 & 1,408 & 89.6 & $p=0.01$ & 1101 & 91.2 & 561 & 93.0 & 540 & 89.4 & $\mathrm{p}=0.03$ \\
\hline Missing & 6 & & 6 & & 0 & & & 1 & & 1 & & 0 & & \\
\hline \multicolumn{15}{|l|}{ Smoking } \\
\hline Never & 1517 & 50.8 & 707 & 49.6 & 810 & 52.0 & & 635 & 53.0 & 319 & 53.1 & 316 & 52.9 & \\
\hline Current & 543 & 18.2 & 258 & 18.1 & 285 & 18.3 & & 193 & 16.1 & 90 & 15.0 & 103 & 17.3 & \\
\hline Ex & 925 & 31.0 & 461 & 32.3 & 464 & 29.8 & $\mathrm{p}=0.30$ & 370 & 30.9 & 192 & 32.0 & 178 & 29.8 & $\mathrm{p}=0.50$ \\
\hline Missing & 18 & & 5 & & 13 & & & 10 & & 3 & & 7 & & \\
\hline \multicolumn{15}{|c|}{ Deprivation index (New Zealand Deprivation Index 2001) } \\
\hline 1 (least deprived) & 422 & 14.5 & 223 & 16.0 & 199 & 13.1 & & 192 & 16.3 & 112 & 19.0 & 80 & 13.5 & \\
\hline 2 & 351 & 12.0 & 182 & 13.0 & 169 & 11.1 & & 147 & 12.5 & 81 & 13.8 & 66 & 11.2 & \\
\hline 3 & 336 & 11.5 & 173 & 12.4 & 163 & 10.7 & & 143 & 12.1 & 75 & 12.7 & 68 & 11.5 & \\
\hline 4 & 343 & 11.8 & 164 & 11.8 & 179 & 11.8 & & 137 & 11.6 & 66 & 11.2 & 71 & 12.0 & \\
\hline 5 & 336 & 11.5 & 151 & 10.8 & 185 & 12.1 & & 126 & 10.7 & 61 & 10.4 & 65 & 11.0 & \\
\hline 6 & 294 & 10.1 & 129 & 9.2 & 165 & 10.8 & & 119 & 10.1 & 53 & 9.0 & 66 & 11.2 & \\
\hline 7 & 248 & 8.5 & 98 & 7.0 & 150 & 9.8 & & 109 & 9.2 & 49 & 8.3 & 60 & 10.2 & \\
\hline 8 & 226 & 7.7 & 106 & 7.6 & 120 & 7.9 & & 90 & 7.6 & 38 & 6.5 & 52 & 8.8 & \\
\hline 9 & 222 & 7.6 & 114 & 8.2 & 108 & 7.1 & & 66 & 5.6 & 33 & 5.6 & 33 & 5.6 & \\
\hline 10 (most deprived) & 142 & 4.9 & 56 & 4.0 & 86 & 5.6 & $\mathrm{p}=0.01$ & 51 & 4.3 & 21 & 3.6 & 30 & 5.1 & $\mathrm{p}=0.13$ \\
\hline Missing & 83 & & 35 & & 48 & & & 28 & & 15 & & 13 & & \\
\hline \multicolumn{15}{|c|}{ Current occupation (New Zealand Standard Classification of Occupations) } \\
\hline 1-Legislators, Administrators \& Managers & 505 & 16.8 & 308 & 21.5 & 197 & 12.5 & & 340 & 28.2 & 170 & 28.2 & 170 & 28.2 & \\
\hline 2-Professionals & 624 & 20.8 & 235 & 16.4 & 389 & 24.8 & & 266 & 22.0 & 133 & 22.0 & 133 & 22.0 & \\
\hline 3-Technicians \& Associate Professionals & 455 & 15.2 & 177 & 12.4 & 278 & 17.7 & & 214 & 17.7 & 107 & 17.7 & 107 & 17.7 & \\
\hline 4-Clerks & 356 & 11.9 & 70 & 4.9 & 286 & 18.2 & & 96 & 8.0 & 48 & 8.0 & 48 & 8.0 & \\
\hline 5-Service \& sales workers & 348 & 11.6 & 88 & 6.2 & 260 & 16.6 & & 112 & 9.3 & 56 & 9.3 & 56 & 9.3 & \\
\hline 6-Agricultural \& Fishery workers & 181 & 6.0 & 120 & 8.4 & 61 & 3.9 & & 94 & 7.8 & 47 & 7.8 & 47 & 7.8 & \\
\hline 7-Trades Workers & 240 & 8.0 & 225 & 15.7 & 15 & 1.0 & & 18 & 1.5 & 9 & 1.5 & 9 & 1.5 & \\
\hline
\end{tabular}


8-Plant \& Machine Operators \& Assemblers

$\begin{array}{ll}179 & 6.0\end{array}$

$150 \quad 10.5$

$29 \quad 1.9$

$28 \quad 2.3$

$14 \quad 2.3$

9-Elementary Workers

$113 \quad 3.8$

$\begin{array}{ll}57 & 4.0\end{array}$

$56 \quad 3.6 \quad \mathrm{p}<0.01$

$\begin{array}{ll}40 & 3.3\end{array}$

$20 \quad 3.3$

$14 \quad 2.3$

Missing 


\begin{tabular}{|c|c|c|c|c|c|c|c|c|}
\hline & \multicolumn{4}{|c|}{ Exposure in males and females (whole sample) } & \multicolumn{4}{|c|}{$\begin{array}{l}\text { Exposure in males and females with the same } \\
\text { occupation (matched sample) }{ }^{\#}\end{array}$} \\
\hline & Total & Male & Female & OR $(95 \% \mathrm{Cl})^{\S}$ & Total & Male & Female & OR $(95 \% \mathrm{Cl})^{\S}$ \\
\hline \multirow[t]{2}{*}{ Exposure } & $n=3003$ & $n=1431$ & $n=1572$ & & $n=1208$ & $\mathrm{n}=604$ & $n=604$ & \\
\hline & $\%$ & $\%$ & $\%$ & & $\%$ & $\%$ & $\%$ & \\
\hline \multicolumn{9}{|l|}{ Dust/chemical factors } \\
\hline Dust & 29.3 & 40.3 & 19.3 & $2.83^{*}(2.40-3.33)$ & 23.2 & 25.0 & 21.4 & $1.24(0.94-1.63)$ \\
\hline Smoke/Fume/Gas & 21.4 & 29.5 & 14.0 & $2.61^{*}(2.17-3.13)$ & 17.6 & 20.2 & 14.9 & $1.54^{*}(1.11-2.14)$ \\
\hline Oils and Solvents & 20.9 & 29.8 & 12.8 & $3.00^{*}(2.48-3.62)$ & 15.2 & 17.9 & 12.4 & $1.62^{*}(1.16-2.27)$ \\
\hline Acids or alkalis & 9.4 & 13.4 & 5.8 & $2.57^{*}(1.98-3.34)$ & 8.0 & 8.8 & 7.1 & $1.35(0.85-2.15)$ \\
\hline Pesticides & 9.6 & 14.5 & 5.0 & $3.14^{*}(2.39-4.11)$ & 8.0 & 8.8 & 7.3 & $1.27(0.75-2.15)$ \\
\hline Any of the above & 45.4 & 57.0 & 34.7 & $2.52^{\star}(2.17-2.92)$ & 38.3 & 41.1 & 35.6 & $1.34^{*}(1.03-1.73)$ \\
\hline \multicolumn{9}{|l|}{ Physical factors } \\
\hline Lifting** & 39.2 & 43.1 & 35.8 & $1.40^{*}(1.21-1.62)$ & 32.3 & 31.6 & 33.1 & $0.98(0.74-1.30)$ \\
\hline Loud noise ${ }^{* *}$ & 29.9 & 40.1 & 20.5 & $2.70^{*}(2.29-3.18)$ & 23.2 & 24.8 & 21.7 & $1.21(0.90-1.63)$ \\
\hline Awkward or tiring positions ${ }^{\star *}$ & 56.1 & 54.5 & 57.6 & $0.91(0.78-1.05)$ & 49.9 & 45.8 & 54.1 & $0.73^{*}(0.57-0.92)$ \\
\hline Awkward grip or hand movements ${ }^{* *}$ & 38.2 & 40.5 & 36.1 & $1.25^{\star}(1.08-1.45)$ & 32.1 & 31.5 & 32.8 & $0.94(0.72-1.22)$ \\
\hline Standing ${ }^{* *}$ & 28.0 & 27.3 & 28.6 & $0.95(0.81-1.11)$ & 24.6 & 24.1 & 25.1 & $0.91 \quad(0.67-1.22)$ \\
\hline Tools that vibrate** & 11.4 & 17.6 & 5.7 & $3.80^{*}(2.94-4.90)$ & 8.2 & 10.3 & 6.2 & $2.06^{*}(1.29-3.29)$ \\
\hline \multicolumn{9}{|l|}{ Organisational factors } \\
\hline Repetitive tasks ${ }^{\star *}$ & 68.2 & 64.7 & 71.5 & $0.76^{*}(0.65-0.89)$ & 63.8 & 61.0 & 66.6 & $0.78(0.59-1.01)$ \\
\hline Working at very high speed** & 51.2 & 47.0 & 55.0 & $0.75^{*}(0.65-0.87)$ & 48.0 & 43.2 & 52.7 & $0.70^{*}(0.55-0.89)$ \\
\hline Working to tight deadlines ${ }^{* *}$ & 73.1 & 74.9 & 71.4 & $1.26^{*}(1.07-1.49)$ & 73.7 & 73.2 & 74.1 & $1.04(0.79-1.36)$ \\
\hline Night shift & 7.1 & 10.2 & 4.3 & $2.57^{\star}(1.89-3.50)$ & 5.7 & 8.0 & 3.4 & $3.32^{*}(1.73-6.36)$ \\
\hline Irregular hours & 16.1 & 20.1 & 12.5 & $1.76^{*}(1.44-2.15)$ & 14.4 & 17.9 & 11.0 & $1.97^{\star}(1.37-2.83)$ \\
\hline \multicolumn{9}{|l|}{ Stress } \\
\hline Not at all-Mildly & 39.7 & 36.6 & 42.6 & 1.00 (ref) & 37.1 & 33.0 & 41.1 & 1.00 (ref) \\
\hline Moderately & 45.2 & 48.5 & 42.2 & $1.36^{*}(1.16-1.59)$ & 46.3 & 49.5 & 43.1 & $1.52^{*}(1.17-1.99)$ \\
\hline Very-Extremely & 15.1 & 15.0 & 15.3 & $1.14(0.92-1.42)$ & 16.6 & 17.5 & 15.8 & $1.43^{*}(1.00-2.05)$ \\
\hline Household responsibility & 34.7 & 29.3 & 39.6 & $0.66^{*}(0.57-0.78)$ & 32.8 & 30.0 & 35.6 & $0.76^{*}(0.59-0.98)$ \\
\hline \multicolumn{9}{|c|}{$\begin{array}{l}\text { \#Males and females matched on current occupation (New Zealand Standard Classification of Occupations } 5 \text {-digit code) } \\
\text { \$adjusted for age } \\
\text { statistically significant at } p<0.05 \\
\star{ }^{*} 1 / 4 \text { of the time or more }\end{array}$} \\
\hline
\end{tabular}


Table 3: Differences in specific occupational exposure prevalence between males and females

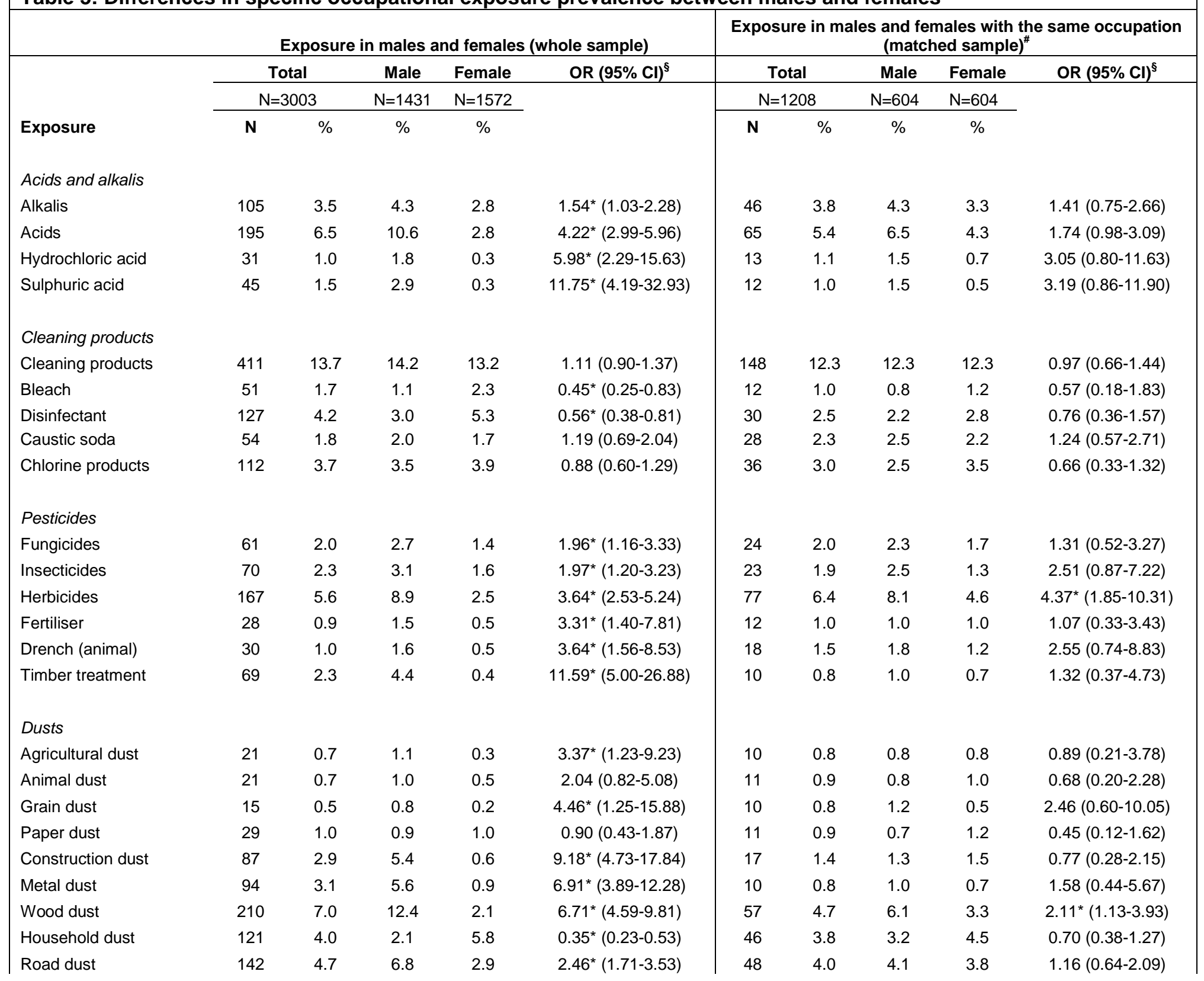




\begin{tabular}{|c|c|c|c|c|c|c|c|c|c|c|}
\hline Flour dust & 17 & 0.6 & 0.8 & 0.3 & $2.61(0.91-7.44)$ & 9 & 0.8 & 1.0 & 0.5 & $2.00(0.49-8.07)$ \\
\hline \multicolumn{11}{|l|}{ Solvents } \\
\hline Solvents & 331 & 11.0 & 15.2 & 7.2 & $2.34^{*}(1.84-2.98)$ & 108 & 8.9 & 10.8 & 7.1 & $1.74^{\star}(1.14-2.64)$ \\
\hline Acetone & 27 & 0.9 & 1.1 & 0.7 & $1.62(0.75-3.51)$ & 9 & 0.8 & 0.7 & 0.8 & $0.97(0.26-3.68)$ \\
\hline Adhesive & 125 & 4.2 & 6.2 & 2.4 & $2.82^{*}(1.91-4.18)$ & 34 & 2.8 & 3.0 & 2.7 & $1.22(0.56-2.66)$ \\
\hline Alcohol & 109 & 3.6 & 3.6 & 3.7 & $0.99(0.67-1.46)$ & 38 & 3.2 & 3.0 & 3.3 & $0.99(0.50-1.95)$ \\
\hline Degreasers & 39 & 1.3 & 2.0 & 0.6 & $3.51^{*}(1.70-7.26)$ & 18 & 1.5 & 1.8 & 1.2 & $1.53(0.55-4.27)$ \\
\hline Methylated spirits & 54 & 1.8 & 1.7 & 1.9 & $0.91(0.53-1.57)$ & 17 & 1.4 & 1.5 & 1.3 & $1.26(0.48-3.31)$ \\
\hline Turpentine & 50 & 1.7 & 2.3 & 1.1 & $2.20^{*}(1.22-3.98)$ & 17 & 1.4 & 1.5 & 1.3 & $1.38(0.52-3.67)$ \\
\hline Formaldehyde & 16 & 0.5 & 0.6 & 0.5 & $1.08(0.40-2.90)$ & 8 & 0.7 & 1.0 & 0.3 & $3.16(0.63-15.78)$ \\
\hline \multicolumn{11}{|c|}{ Engine fuels and emissions } \\
\hline Diesel engine emission & 72 & 2.4 & 4.2 & 0.8 & $5.78^{\star}(3.09-10.80)$ & 18 & 1.5 & 1.8 & 1.2 & $1.51(0.57-3.95)$ \\
\hline Diesel fuel & 46 & 1.5 & 3.0 & 0.2 & $16.40 *(5.07-53.04)$ & 7 & 0.6 & 1.0 & 0.2 & $7.42(0.87-63.11)$ \\
\hline Engine emission & 183 & 6.1 & 8.7 & 3.7 & $2.59^{*}(1.88-3.57)$ & 82 & 6.8 & 7.6 & 6.0 & $1.38(0.83-2.29)$ \\
\hline Engine oil & 98 & 3.3 & 6.1 & 0.7 & $9.52^{*}(5.06-17.92)$ & 28 & 2.3 & 2.8 & 1.8 & $1.73(0.78-3.85)$ \\
\hline Kerosene & 17 & 0.6 & 1.1 & 0.1 & $18.34^{*}(2.43-138.73)$ & 3 & 0.3 & 0.3 & 0.2 & $1.93(0.17-21.32)$ \\
\hline Petrol fuel & 25 & 0.8 & 1.5 & 0.2 & $8.35^{\star}(2.49-27.99)$ & 6 & 0.5 & 0.7 & 0.3 & $2.59(0.46-14.63)$ \\
\hline $\begin{array}{l}\text { Petrol fumes } \\
\text { Liquefied petroleum gas }\end{array}$ & 26 & 0.9 & 1.3 & 0.5 & $3.13^{*}(1.31-7.48)$ & 7 & 0.6 & 0.5 & 0.7 & $0.59(0.13-2.76)$ \\
\hline (LPG) & 39 & 1.3 & 2.3 & 0.4 & $6.78^{\star}(2.82-16.28)$ & 16 & 1.3 & 1.8 & 0.8 & $2.55(0.86-7.52)$ \\
\hline $\begin{array}{l}\text { Environmental tobacco } \\
\text { smoke (ETS) }\end{array}$ & 36 & 1.2 & 0.6 & 1.7 & $0.36^{\star}(0.17-0.77)$ & 12 & 1.0 & 0.8 & 1.2 & $0.66(0.21-2.12)$ \\
\hline \multicolumn{11}{|l|}{ Machinery oils and fumes } \\
\hline Machinery oils & 42 & 1.4 & 2.5 & 0.5 & $5.58^{*}(2.47-12.61)$ & 8 & 0.7 & 0.8 & 0.5 & $1.49(0.34-6.54)$ \\
\hline Machinery fumes & 28 & 0.9 & 1.5 & 0.4 & $4.13^{\star}(1.67-10.22)$ & 9 & 0.8 & 0.8 & 0.7 & $1.40(0.36-5.43)$ \\
\hline Hydraulic oil & 30 & 1.0 & 2.0 & 0.1 & $34.57^{*}(4.70-254.23)$ & 5 & 0.4 & 0.7 & 0.2 & $4.82(0.53-43.69)$ \\
\hline Lubricants & 76 & 2.5 & 4.3 & 1.0 & $4.81^{*}(2.71-8.52)$ & 20 & 1.7 & 1.5 & 1.8 & $0.82(0.33-2.01)$ \\
\hline Cutting fluids & 20 & 0.7 & 1.3 & 0.1 & $10.48^{*}(2.42-45.34)$ & 5 & 0.4 & 0.7 & 0.2 & $4.23(0.47-37.92)$ \\
\hline Welding & 88 & 2.9 & 5.9 & 0.2 & $33.66^{\star}(10.61-106.76)$ & 11 & 0.9 & 1.5 & 0.3 & $5.25^{\star}(1.10-25.10)$ \\
\hline \multicolumn{11}{|l|}{ Ink and dyes } \\
\hline Dyes & 23 & 0.8 & 1.1 & 0.5 & $2.60 *(1.06-6.36)$ & 12 & 1.0 & 1.3 & 0.7 & $1.92(0.58-6.40)$ \\
\hline Printing & 16 & 0.5 & 1.1 & 0.1 & $17.37^{\star}(2.29-131.92)$ & 7 & 0.6 & 1.0 & 0.2 & $7.08(0.85-59.18)$ \\
\hline Inks & 32 & 1.1 & 1.4 & 0.8 & $1.94(0.94-4.01)$ & 15 & 1.2 & 1.3 & 1.2 & $1.40(0.46-4.23)$ \\
\hline Hair dyes & 11 & 0.4 & 0.1 & 0.6 & $0.12^{*}(0.02-0.93)$ & 1 & 0.1 & 0.0 & 0.2 & \\
\hline \multicolumn{11}{|l|}{ Fibres } \\
\hline Fibreglass & 20 & 0.7 & 1.3 & 0.1 & $10.70^{*}(2.47-46.32)$ & 4 & 0.3 & 0.3 & 0.3 & $0.87(0.12-6.24)$ \\
\hline
\end{tabular}




\begin{tabular}{|c|c|c|c|c|c|c|c|c|c|c|}
\hline Insulation material & 27 & 0.9 & 1.8 & 0.1 & $14.29^{*}(3.37-60.56)$ & 4 & 0.3 & 0.5 & 0.2 & $2.91(0.30-28.21)$ \\
\hline Textile dust & 69 & 2.3 & 1.2 & 3.3 & $0.34^{*}(0.20-0.60)$ & 25 & 2.1 & 1.5 & 2.7 & $0.59(0.26-1.34)$ \\
\hline Paint and lacquers & 151 & 5.0 & 8.2 & 2.2 & $4.17^{\star}(2.82-6.16)$ & 45 & 3.7 & 4.1 & 3.3 & $1.35(0.72-2.53)$ \\
\hline Paint fumes & 47 & 1.6 & 2.7 & 0.6 & $4.74^{*}(2.28-9.86)$ & 16 & 1.3 & 1.5 & 1.2 & $1.26(0.46-3.45)$ \\
\hline Acrylic paint & 20 & 0.7 & 0.5 & 0.8 & $0.62(0.25-1.56)$ & 8 & 0.7 & 0.2 & 1.2 & $0.15(0.02-1.26)$ \\
\hline Paint dust & 17 & 0.6 & 1.1 & 0.1 & $19.25^{\star}(2.54-145.57)$ & 3 & 0.3 & 0.3 & 0.2 & $1.88(0.17-20.72)$ \\
\hline
\end{tabular}

